\title{
Knowledge and attitudes on gender equality and their correlates among the second year students of University of Colombo
}

\author{
M.N. Vidanapathirana, S. Varothayan, D.C. Vilochani, C. Wangmo, H. Jayakody \\ Faculty of Medicine, University of Colombo
}

\author{
A R T I C L E I N F O \\ Article history: \\ Submission 11.02.17 \\ Acceptance 16.05.17 \\ Available online \\ DOI: \\ http://doi.org/10.4038/cjms.v54i1.4806
}

Keywords:

Under graduates

Gender

Gender-equality

Knowledge

Attitudes

University students

\begin{abstract}
Background: Gender equality is a significant determinant of the health and national development of a country. As future leaders, undergraduates need sufficient knowledge and favorable attitudes towards gender equality, to enable gender-equitable socio-economic decision-making.
\end{abstract}

Objectives: This study aimed to assess the level of knowledge and attitudes on gender equality and describe their correlates among the second year students of University of Colombo.

Methods: This was a descriptive, cross-sectional study conducted among 388 second year students selected through multistage random sampling in the faculties of Arts, Management, Science and Computing in University of Colombo. A self-administered questionnaire was employed to gather information and data was analyzed using descriptive statistics and Chisquare test.

Results: The results revealed that a majority of respondents had a satisfactory level of overall knowledge on gender equality, with a mean of $59.28 \%$ (SD-13.53). However, knowledge on practical aspects such as gender equity, gender mainstreaming, gender legislature and gender equality indicators in Sri Lanka were not satisfactory. The majority of the respondents had favorable attitudes towards gender equality (55.1\%) and its various aspects. Positive attitudes were found to be associated with female sex $(\mathrm{p}=0.0001, \mathrm{X} 2=47.230, \mathrm{~d}=2)$, higher level of paternal $(\mathrm{p}=0.005, \mathrm{x} 2$ $=7.787, \mathrm{df}=1)$ and maternal education $(\mathrm{p}=0.004, \mathrm{x} 2=8.149, \mathrm{df}=1)$, paternal employment $(\mathrm{p}=0.014, \mathrm{X} 2=6.100, \mathrm{df}=1)$ and higher level of respondent knowledge on gender equality $(\mathrm{p}=0.002, \mathrm{X} 2=9.335, \mathrm{df}=1)$.

Conclusions: Knowledge on gender equality was satisfactory and attitudes towards it were favorable among selected group of university undergraduates. However, knowledge on practical aspects of gender equality was poor.

\section{Background}

The United Nations defines gender as the "social attributes and opportunities associated with being male and female and the relationships between women and men and girls and boys, as well as the relations between women and those between men"1. The same body defines gender equality as

\section{Corresponding Author:}

M. N. Vidanapathirana

manudi.vidanapathirana@gmail.com

http://orcid.org/0000-0002-0725-1238 equal rights, responsibilities and opportunities for males and females [1].

Gender equality is a significant determinant of the health of a country due to issues of gender-based violence (domestic violence, sexual violence, forced commercial sex and female genital mutilation). Furthermore, women's access to education and healthcare are hindered through inequality and the sectors of women's health and maternal health suffer significantly [2].

(d) This is an open-access article distributed under the terms of the Creative Commons Attribution License, which permits unrestricted use, distribution, and reproduction in any medium, provided the original author and source are credited. 
The United Nations has duly recognized the importance of gender equality and included it in the seventeen Sustainable Development Goals (SDGs) that provide a holistic approach for global development. SDG number 5 reads 'achieve gender equality and empower all women and girls' [3]. Sri Lanka being a UN signatory country is bound in a promise to achieve these goals.

Sri Lanka has achieved impressive gender equality in education. However, the labor market, the senior executive decision-making level and the political sphere, stand out due to its notably inadequate female representation [4]. Sri Lanka also reflects poorly in gender-based violence. There are regional disparities within the country, in terms of even in the promising gender equality indicators like education [5].

There are often deeper cultural issues connected to gender-related practices. The way the community and policy makers perceive gender equality and their attitudes towards it, are central in achieving equality on realistic grounds [6].

Research on knowledge and attitudes on gender equality is poor in Sri Lanka. Although communitybased research has been conducted in Sri Lanka to assess attitudes and practices towards certain aspects of gender issues [gender based violence (GBV) and sexual violence], no studies have assessed both knowledge and attitudes on gender equality as a whole, among the Sri Lankan community or its youth [7].

This study will bridge the existing knowledge gap by assessing knowledge and attitudes towards gender equality among a segment of educated youth in the country. As the future administrators, educators and policy makers of the country, undergraduates require sufficient knowledge and positive attitudes towards gender equality, to make gender-equitable socio-economic decisions for national development.

\section{Objectives}

This study aimed to assess the level of knowledge and attitudes on gender equality and describe their correlates among the second year students of University of Colombo.

\section{Methods}

The study was a university-based descriptive crosssectional study carried out in October and November 2015. Ethical approval to conduct the study was obtained from the Ethics Review Committee of the Faculty of Medicine, Colombo and administrative approval to conduct the study was obtained from the university authorities.

Second year undergraduates enrolled in different streams (arts, computing, education, law, management and finance, medicine, science) in University of Colombo were considered for the study. Foreign students were excluded. The sample size estimate was calculated by applying the statistical formula by Lwanga \& Lemeshow [8] with the anticipation of a 5\% non-response rate.

Multistage random sampling technique was used to identify the study participants. Four faculties were chosen at random. Strata were drawn from the four randomly selected faculties and the required number from each faculty was calculated proportionately by considering the different numbers of students enrolled in the second-year. Within each faculty, the required number of students were randomly selected from the register of second year undergraduates available at the Office of the Senior Assistant Registrar.

A pre-tested self-administered questionnaire was employed to gather information. It included variables on socio demographic characteristics of the participant, knowledge on gender equality and attitudes towards gender equality. Face validity and content validity were assessed by consulting a group of experts consisting of a gender expert, a sociologist and a public health expert for relevance of each of the items in assessing knowledge and attitudes. The appropriateness of the wording used and the acceptability of the items to the local context were assessed. Questionnaires were printed in Sinhala, English and Tamil.

There were ten closed-ended questions in the knowledge component. Knowledge on the aspects of concepts of gender equality, gender equity (elimination of inequalities and discrimination between women and men to ensure equal opportunities $^{9}$ ) and gender mainstreaming (the process of assessing the implications for women and men of any planned action, including legislation, policies or programmes, in all areas and at all levels ${ }^{1}$ ), legal provisions available for achieving gender equality and gender equality indicators in Sri Lanka-were assessed. 
Attitudes were measured by ten questions derived from standard gender attitudinal scales [10]. Attitudes towards the concept of gender equality, female education, female engagement in politics, household dynamics, contraceptive responsibility, gender-based violence, sexual violence and the dowry system, were inquired into. The answers were given in the form of a five point Likert scale. The questionnaire comprised of quantitative data. Data entry and analysis were done using the computer package SPSS 20.

Socio demographic variables were described using frequencies and percentages and knowledge and attitudes were analyzed using descriptive statistics (frequency, mean, SD). The statistical association between knowledge, attitudes and their correlates were evaluated using the Chi square test.

The knowledge score was calculated on a $0-10$ scale. The marks obtained for each question were added and the total mark converted into a percentage. The percentage of knowledge score was categorized with consultation from a gender expert. Marks from 0-50\% were considered to be a low level of knowledge and marks from 51-100\% were considered to be a high level of knowledge. This was further divided as very poor $(0-25 \%)$, poor $(26-50 \%)$, satisfactory $(51-75 \%)$ and good (76-100\%).

The responses to the statements on attitudes contained five answers which were put into a 5 point Likert scale (Strongly disagree, Disagree, Neutral, Agree, Strongly agree). For each statement on a positive attitude, a 'Strongly agree' response scored +2 , 'Agree' scored +1 , 'Neutral' scored 0, 'Disagree' scored (-1) and 'Strongly disagree' scored (-2). For each statement on a negative attitude, 'Strongly disagree' scored +2 , 'Agree' scored +1 , 'Neutral' scored 0, 'Agree' scored (-1) and 'Strongly agree' scored (-2).

The total score for each respondent was calculated by summing up the score obtained for each statement. The cut-off point for categorizing attitudes was decided upon with consultation from a gender expert. The selected cut-off point was $50 \%$ of the highest possible score $(50 / 100 * 20=10)$ and attitudes were accordingly categorized into two groups. Those below the cut-off point were considered to be unfavorable and those equal to and above it were considered to be favorable.

When assessing correlates, certain sociodemographic variables such as underrepresented religions and ethnicities were amalgamated for yielding better and more precise analytical results.

\section{Results}

Four hundred and three university students who fulfilled the inclusion criteria were approached. The response rate for the study was $96.28 \%$ bringing the final sample size to 388 . The socio-demographic characteristics of the study population are shown in table 1 .

Table 1: Frequency distribution of socio-demographic characteristics of the respondents $(n=388)$

\begin{tabular}{lll}
\hline Characteristic & No. of respondents (n) & Percentage (\%) \\
\hline & & \\
Faculty (n=388) & & \\
Faculty of Arts & 144 & 37.1 \\
Faculty of Management & 89 & 22.9 \\
Faculty of Science & 99 & 25.5 \\
School of Computing & 56 & 14.5 \\
Age (n=337) & & \\
=20 years & 6 & 1.8 \\
21-25 years & 317 & 94.1 \\
$>26$ years & 14 & 4.1 \\
Sex (n=386) & & \\
Male & 159 & 41.2 \\
Female & 227 & 58.8 \\
\hline
\end{tabular}




\begin{tabular}{lll} 
Ethnicity (n=388) & \\
Sinhala & 372 & 95.8 \\
Tamil & 3 & 0.8 \\
Muslim & 10 & 2.6 \\
Burgher & 2 & 0.5 \\
Other & 1 & 0.3 \\
& & \\
Religion (n=388) & 348 & 89.7 \\
Buddhist & 2 & 0.5 \\
Hindu & 10 & 2.6 \\
Islam & 25 & 6.4 \\
Christian & 3 & 0.8 \\
Other & & \\
Civil status (n=388) & 19 & 4.9 \\
Married & 369 & 95.1 \\
Unmarried and other & 144 & 39.0 \\
\hline Relationship status & \\
Currently in a relationship & 107 & 29.0 \\
Previously in a relationship & 118 & 32.0 \\
Never in a relationship & $\mathbf{3 8 8}$ & $\mathbf{1 0 0}$ \\
\hline Total & & \\
* Other refers to respondents who were divorced (n=1) & \\
& & \\
& &
\end{tabular}

The level of overall knowledge on gender equality of the study population is shown in table 2 .

Table 2: Frequency distribution of respondents by knowledge score on gender equality

\begin{tabular}{llll}
\hline Level of Knowledge & No. of students (n) & Percentage (\%) \\
& & & \\
\hline Low & Very poor (0-25\%) & 5 & 1.33 \\
& & & \\
& Poor (26-50\%) & 119 & 31.82 \\
& Total & 124 & 33.15 \\
& & & \\
High & Satisfactory & 211 & 56.42 \\
& $(51-75 \%)$ & & 10.43 \\
& Good (76-100\%) & 39 & 66.85 \\
\hline Total & Total & 250 & 100 \\
\hline
\end{tabular}


The results revealed that a majority of respondents had a high level of overall knowledge on gender equality, with a mean of $59.28 \%$ (SD-13.53).

Knowledge was also analyzed separately in accordance with the individual components of knowledge tested.

With regard to knowledge on concepts of gender equality, $72.4 \%(n=281)$ had good knowledge on gender equality as a concept. Some of the respondents $(19.6 \%, \mathrm{n}=76)$, had some knowledge on it and a few $(7.9 \%, \mathrm{n}=31)$ had no knowledge at all. The majority $(79.4 \%, n=308)$ were unaware of the concept of gender equity and a significant percentage $(41.1 \%, \mathrm{n}=158)$ lacked knowledge on the concept of gender mainstreaming.

With regard to relevant legislature, the majority knew of the existence of an anti-domestic violence law $(90.9 \%, \mathrm{n}=349)$ and an anti-rape law $(91.2 \%$, $\mathrm{n}=350$ ) in Sri Lanka. However, a substantial proportion $(84.4 \%, n=324)$ were unaware that an anti-intimate partner violence law is deficient in Sri Lanka.
With regard to gender equality indicators, only a minor proportion of respondents $(15.7 \%, n=60)$ were aware that Sri Lanka has achieved gender equality in primary education. A little over half of the respondents $(54.9 \%, \mathrm{n}=211)$ were aware that male to female ratio in the labor force in Sri Lanka is unequal and more than three quarters $(81.7 \%$, $\mathrm{n}=313$ ) were aware that male to female ratio in Sri Lankan politics is unequal.

Attitudes on gender equality among the study population were mostly favorable $(55.1 \%, \mathrm{n}=207)$. Attitudes towards individual aspects of gender equality that were tested, also yielded a favorable majority.

Analysis of correlates revealed that the only correlate with a statistically significant difference in knowledge among different groups was the employment status of the father $(\mathrm{p}=0.011)$. Those whose fathers had never been employed had lower levels of knowledge on gender equality compared to those whose fathers are either currently employed or had previously been employed.

Correlates affecting attitudes are shown in Table 3.

Table 3: Attitudes towards gender equality according to correlates affecting them among respondents

\begin{tabular}{|c|c|c|c|c|c|c|}
\hline \multirow[t]{3}{*}{ Correlate } & \multicolumn{4}{|c|}{ Attitude } & \multirow[t]{3}{*}{ Total } & \multirow{3}{*}{$\begin{array}{l}\text { Significa } \\
\text { nce }\end{array}$} \\
\hline & \multicolumn{2}{|c|}{ Favorable } & \multicolumn{2}{|c|}{ Unfavorable } & & \\
\hline & Number & $(\%)$ & Number & $(\%)$ & & \\
\hline \multicolumn{7}{|l|}{ Sex } \\
\hline Male & 54 & $34.4 \%$ & 103 & $65.6 \%$ & 157 & \multirow{3}{*}{$\begin{array}{l}\mathrm{p}<0.0001 \\
X^{2=} 47.23 \\
0 \\
\mathrm{df}=2\end{array}$} \\
\hline Female & 151 & $69.6 \%$ & 66 & $30.4 \%$ & 217 & \\
\hline Total & 205 & & 169 & & 374 & \\
\hline \multicolumn{7}{|l|}{ Ethnicity } \\
\hline Sinhala & 200 & $55.4 \%$ & 161 & $44.6 \%$ & 361 & \multirow{3}{*}{$\begin{array}{l}P=0.505 \\
X^{2}=0.444 \\
d f=1\end{array}$} \\
\hline Non-Sinhala * & 7 & $46.7 \%$ & 8 & $53.3 \%$ & 15 & \\
\hline Total & 207 & & 169 & & 376 & \\
\hline \multicolumn{7}{|l|}{ Religion } \\
\hline Buddhist & 185 & $54.6 \%$ & 154 & $45.4 \%$ & 339 & \multirow{3}{*}{$\begin{array}{l}P=0.570 \\
X^{2}=0.322 \\
d f=1\end{array}$} \\
\hline Other $* *$ & 22 & $59.5 \%$ & 15 & $40.5 \%$ & 37 & \\
\hline Total & 207 & & 169 & & 376 & \\
\hline
\end{tabular}




\section{Relationship status}

Currently in a

relationship

Previously in a

relationship

Never been in a

relationship

Total

\begin{tabular}{|c|c|c|c|c|c|}
\hline 81 & $57.9 \%$ & 59 & $42.1 \%$ & 140 & $\begin{array}{l}P=0.706 \\
X^{2}=0.697\end{array}$ \\
\hline 58 & $55.2 \%$ & 47 & $44.8 \%$ & 105 & $\mathrm{df}=2$ \\
\hline 60 & $52.6 \%$ & 54 & $47.4 \%$ & 114 & \\
\hline 199 & & 160 & & 359 & \\
\hline
\end{tabular}

Type of school

attended

Girls' school

Boys' school

Mixed school

Both single sex and mixed schools

Total

$\begin{array}{ll}92 & 73.6 \% \\ 27 & 34.2 \% \\ 68 & 47.6 \% \\ 20 & 69.0 \%\end{array}$

207

169

$26.4 \%$
$65.8 \%$
$52.4 \%$
$31.0 \%$

125

79

143

29

376

\section{Highest education}

level of father

Below A/L

A/L and above

Total

$45.7 \%$

$60.5 \%$

75

94

169

$\begin{array}{ll}54.3 \% & 138 \\ 39.5 \% & 238 \\ & 376\end{array}$

$\mathrm{P}=0.005$

$(<0.01)$

$\mathrm{X}^{2=} 7.787$

$\mathrm{df}=1$

Highest education level of mother

Below A/L

AL and above

59

148

$45.0 \%$

$60.4 \%$

72

97

169

$\begin{array}{ll}55.0 \% & 131 \\ 39.6 \% & 163 \\ & 375\end{array}$

$\mathrm{P}=0.004$

$(<0.01)$

$\mathrm{X}^{2=} 8.149$

$\mathrm{df}=1$

Employment status of

father

Currently or

203

previously employed

Never employed

Total

4
207

$56.4 \%$

157

$25.0 \%$

12

169

$\begin{array}{rr}43.6 \% & 360 \\ 75.0 \% & 16 \\ & 376\end{array}$

$\mathrm{P}=0.014$

$(<0.05)$

$\mathrm{X}^{2=} 6.100$

$\mathrm{df}=1$

Employment status of mother

Currently or

previously employed

Never employed

Total

* Tamil, Muslim, Burgher and other $\quad * *$ Hindu, Islam and other
Positive attitudes were found to be associated with female $\operatorname{sex}\left(\mathrm{p}<0.0001, \mathrm{X}^{2=} 47.230, \mathrm{df}=2\right)$, higher level of paternal education $\left(\mathrm{p}=0.005, \mathrm{x}^{2}=7.787\right.$, $\mathrm{df}=1)$, higher level of maternal education $(\mathrm{p}=0.004$, $\left.\mathrm{x}^{2}=8.149, \mathrm{df}=1\right)$, paternal employment $(\mathrm{p}=0.014$, $\left.\mathrm{X}^{2}=6.100, \mathrm{df}=1\right)$ and higher level of respondent knowledge $\left(\mathrm{p}=0.002, \mathrm{X}^{2}=9.335, \mathrm{df}=1\right)$.

Ceylon Journal of Medical Science 54(1):35-43 (2017)
For each aspect of attitudes tested, the percentage of males with unfavorable attitudes was higher than that of females. The unfavorable nature in male attitudes compared to females was statistically significant for all attitudinal aspects, except for attitudes towards sharing of household chores and contraceptive responsibilities. 


\section{Discussion}

Previous studies on gender equality in Sri Lanka have tended to focus only on individual issues of gender, such as GBV and sexual violence [7]. This study was therefore, a pioneering study encompassing several domains of gender equality and reflected a complete picture of knowledge and attitudes towards the entirety of gender equality in a segment of Sri Lankan youth engaged in tertiary education.

University of Colombo is an institute of tertiary education that nurtures students from different socio-economic backgrounds from all 24 districts of the country. The random sampling method used enabled unbiased representation of all these groups. A self-administered questionnaire was used in this educated study group to enhance feasibility of data collection in a large study sample and facilitate prompt testing of diverse domains and correlates. An added advantage was the elimination of interviewer-bias.

The response rate for the study was $96.28 \%$ $(\mathrm{n}=388)$. The majority of the study population was Sinhala $(95.8 \%, \mathrm{n}=372)$ and Buddhists $(89.7 \%$, $\mathrm{n}=348$ ) and the rest belonged to diverse ethnicities and religions. While these were important variables in assessing attitudes towards gender equality, the ethnic and religious composition of respondents did not reflect national proportions [11].

The mean knowledge score of the respondents was $59.28 \%$ (SD-13.53), which was a satisfactory score. This high score could be due to their educational status as corroborated by Alim and Rashid's study in 2005, which revealed that higher educational level was associated with higher knowledge on gender equality [12]. However, it should not be neglected that although less than half, $33.15 \%(\mathrm{n}=124)$ of respondents, had a low knowledge level ( $<50 \%$ knowledge score). This was quite a significant proportion and low knowledge levels on gender equality among future policy makers can have dire consequences on national development.

The study revealed that most participants were aware of the concept of gender equality, which could be due to public propaganda on the matter. However, they were oblivious of newly emerging concepts which take into consideration the physiological and circumstantial differences between males and females in policy making i.e. gender equity and gender mainstreaming. These latter concepts bear pragmatic importance and knowledge on these among undergraduates is therefore, vital [13].

With regard to knowledge on gender legislature, $84.4 \%(\mathrm{n}=324)$ were unaware that an anti-intimate partner violence law to protect women from acts of intra-marital rape is deficient in Sri Lanka. Sufficient knowledge on legislative shortcomings is essential to pave way for constructive legal reforms.

Attitudes towards gender equality among participants were mostly favorable, with $55.1 \%$ $(n=207)$ of respondents showing positive attitudes. This contrasted with the findings of De Mel and others in 2013, where community-derived participants from Colombo, Hambantota, Batticoloa and Nuwara Eliya had shown mostly genderinequitable attitudes [14]. The difference could be because the education level of undergraduates allowed uninhibited thinking in comparison to community-based subjects whose thinking is more likely to be governed by social and cultural norms. Moreover, the exposure of undergraduates to both male and female educators and other professionals may have contributed to their favorable attitudes. On the other hand, it is quite possible that the quantitative method of data collection had overlooked subtle negativities in undergraduate attitudes and social desirability bias had played a role.

Attitudes of respondents towards different aspects of gender equality were also quite positive. The different aspects of attitudes assessed were, gender equality as a concept, education, politics, the dowry system, household chores and domestic decision making, contraceptive responsibility, gender based violence and sexual violence.

The latter four aspects had been tested in De Mel's study ${ }^{14}$. Significant differences between the community and undergraduates were seen in the findings for all these aspects, with undergraduates responding more favorably, probably due to the aforementioned reasons.

With regard to correlates for knowledge, only paternal employment status created a statistically significant difference in knowledge among

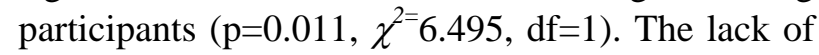
associations with other socio-demographic correlates may be due to the selection of participants from a single educational institute, which homogenized their knowledge levels to some degree. Additionally, their knowledge levels could be largely correlate-independent, due to habitual 
utilization of sources of information (books, newspapers, internet etc.).

Contrastingly, correlates for attitudes towards gender equality were five-fold; sex of the respondent, level of paternal education, level of maternal education, paternal employment and level of knowledge. An association between positive gender attitudes and female sex was apparent $\left(p<0.0001, \chi^{2=} 47.230, d f=2\right)$. Females showed more favorable attitudes than males with respect to the concept of gender equality, equal education, female participation in politics, domestic decision making, gender based violence, sexual violence and the dowry system. In Alim and Rashid's study from Bangladesh, a difference in male and female attitudes was seen only in relation to gender based violence, where more males had shown positive attitudes ${ }^{12}$. This positive male attitude may have been due to social desirability bias which would have been more influential in the intervieweradministered data collection method used.

It was interesting to note that more undergraduate males $(58.2 \%, \mathrm{n}=92)$ compared to males in the community felt that a man should, in fact have the final say about household decisions ${ }^{13}$. More than half of male undergraduates $(52.5 \%, \mathrm{n}=83)$ also felt that a man should be the primary earner of a family. This increase in negative attitudes among undergraduate males could be due to the fact that they have been overachievers throughout their lives and therefore feel a sense of dominance, more so than the common man.

Associations for favorable attitudes were also seen with a higher level of paternal education $(\mathrm{p}=0.005$, $\chi^{2}=7.787, \mathrm{df}=1$ ), higher level of maternal education $\left(\mathrm{p}=0.004, \quad \chi^{2}=8.149, \quad \mathrm{df}=1\right) \quad$ and paternal

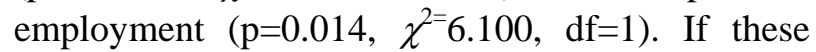
factors could be equated to higher socio-economic status by proxy, then the findings co-align with those of Alim and Rashid's study, which revealed that higher economic status led to more gender favorable attitudes ${ }^{12}$. Their study also revealed differences in attitudes based on religions [12], which the present study failed to elicit. Reasons for the failure may be the underrepresentation of certain ethnic and religious groups during sampling and the consolidation of inadequately represented religions and ethnicities for ease of data analysis in the present study. Amalgamation of certain ethnic and religious groups with attitudinal differences between them may have occurred through this.
Another important finding in this study to be noted was that a statistically significant association was found between higher levels of knowledge and favorable attitudes $\left(\mathrm{p}=0.002, \chi^{2=} 9.335, \mathrm{df}=1\right)$. This is an optimistic finding as it implies that attitudes could be changed for the better if undergraduates are given sufficient knowledge.

Overall, the study explored previously unchartered grounds and had a large sample size $(n=388)$ with good socio-demographic diversity. Limitations of the study included lack of generalizability due to the exclusive nature of the study population, researcher imposition when selecting knowledge questions and the use of quantitative data when analyzing attitudes. Though qualitative data would have provided more accurate and meaningful information, this method had to be waived due to the time and resource constraints. Additionally, the willingness to participate in a time consuming, verbal data collection session would have been less.

\section{Conclusions}

A key factor deduced from these findings is that although, knowledge on gender equality among respondents was satisfactory, knowledge on practical matters of gender equality was inadequate. Attitudes of the majority were favorable, but varied according to sex and other socio-economic status. Knowledge on gender equality is the only modifiable correlate for more favorable attitudes.

\section{Acknowledgement}

We would like to acknowledge the Department of Community Medicine, Faculty of Medicine, Colombo for their guidance and the administrative staff of University of Colombo for their support.

\section{References}

1. OCHA Gender Toolkit. [Internet]. Office for the Coordination of Humanitarian Affairs, United Nations Policy Development and Studies Branch, United Nations, New York; [cited 2017May]. Available from: https://docs.unocha.org/sites/dms/documents/g endertoolkit1_121205_5_ver7.pdf

2. Coverdell PD. Global Issues | Gender Equality and Women's Empowerment [Internet]. Peace Corps, United States; [cited 2017May]. Available from: http://www.peacecorps.gov/wws/articles/globa l-issues-gender-equality-and-womensempowerme/ 
3. Sustainable Development Goals [Internet]. United Nations; [cited 2017Jan]. Available from: http://www.un.org/sustainabledevelopment/sus tainable-development-goals/

4. Jayaweera S, Wijemanne H, Wanasundara L, Vitarana KM. Gender Dimensions of the Millennium Development Goals in Sri Lanka. Colombo, United Nations Development Programme, Centre for Women's Research. 2007;

5. United Nations Development Programme. Sri Lanka National Human Development Report 2014. Colombo, UNDP. 2014;

6. Pittman A. Fast-Forwarding Gender Equality and Women's Empowerment? [Internet]. New York, United Nations Development Programme.; 2014 [cited 2017May]. Available from:

http://web.undp.org/evaluation/documents/arti cles-

papers/occasional_papers/Occasional\%20Pape r_Gender_Pittman\%20.pdf

7. Women's Health Committee. Review of Research Evidence on Gender Based Violence (GBV) in Sri Lanka. Second Edition. Colombo: Sri Lanka Medical Association; 2011. (ISBN 978-955-9386-23-0).

8. Lwanga, S.K., Lemeshow, S. (1991) Sample size determination in health studies: a practical manual. Geneva, World Health Organization

9. Open Learning Communities [Internet]. United Nations Educational, Scientific and Cultural Organization; [cited 2015Dec]. Available from http://portal.unesco.org/ci/en/ev.phpURL_ID $=3443 \&$ URL_DO=DO_TOPIC\&UR L_SECTION $=201 . h t m l$ [Accessed $1^{\text {st }}$ May 2017]
10. Compendium of Gender Scales [Internet]. CChange, fhi 360, USAID; [cited 2017May]. Available from: https://www.cchangeprogram.org/content/gender-scalescompendium/index.html

11. The World Factbook [Internet] Central Intelligence Agency, United States; [cited 2017May]. Available from: https://www.cia.gov/library/publications/theworld-factbook/geos/ce.html. 2017;

12. Alim MA, Rashid AT. Building Positive Attitudes Towards Gender Equality: A Baseline Survey of Gender Quality Action Learning Programme. Dhaka, BRAC Research and Evaluation Division. 2005; [cited 2017May]. Available from: http://research.brac.net/reports/GQAL.pdf

13. Concepts and Definitions [Internet]. United Nations WOMEN; [cited 2017May]. Available from:

http://www.un.org/womenwatch/osagi/concept sandefinitions.htm

14. De Mel N, Peiris P, Gomez S. Broadening gender: Why masculinities matter- Attitudes, Practices and Gender-based Violence in four districts in Sri Lanka. Colombo, United Nations, Partners for Prevention. 2013; [cited 2017May]. Available from: http://www.care.org/sites/default/files/docume nts/Broadening-Gender_Why-MasculinitiesMatter.pdf 